\title{
cmaJOPEN
}

\section{Food insecurity during COVID-19 in a Canadian academic pediatric hospital: a cross-sectional survey}

\author{
Meta van den Heuvel MD PhD, Anne Fuller MD MS, Nusrat Zaffar MS, Xuedi Li MSc, \\ Carolyn E. Beck MD MSc, Catherine S. Birken MD MSc
}

Abstract

Background: Hospital-based food insecurity is defined as the inability of caregivers to obtain adequate food during their child's hospital admission. We aimed to measure the prevalence of household and hospital-based food insecurity, and to explore the associations with caregiver distress in an academic pediatric hospital setting.

Methods: We conducted a cross-sectional survey of caregivers of children admitted to the general pediatric ward of an academic pediatric hospital in Toronto, Ontario, from April to October 2020. We measured household food insecurity using the 18-item Household Food Security Survey Module, and included 3 adapted questions about hospital-based food insecurity. We measured caregiver distress with the Distress Thermometer for Parents. We used descriptive statistics to assess the proportion of respondents with food insecurity, and linear regression models to explore the relation of household (adult and child) and hospital-based food insecurity with caregiver distress. We used thematic analysis to explore caregivers' feedback.

Results: We contacted 851 caregivers, and 775 (91.1\%) provided consent to participate. Overall, 430 (50.5\%) caregivers completed at least part of the survey. Caregivers described a high prevalence of household $(34.2 \%)$ and hospital-based (38.1\%) food insecurity. Adult $(\beta=0.21,95 \%$ confidence interval $[\mathrm{Cl}] 0.07-0.36)$, child $(\beta=0.38,95 \% \mathrm{Cl} 0.10-0.66)$ and hospital-based $(\beta=0.56,95 \% \mathrm{Cl}$ $0.30-0.83$ ) food insecurity were significantly associated with caregiver distress, independent of covariates. We identified financial burden, emotional and practical barriers, stress obtaining food and advocacy for food as important themes in caregiver feedback.

Interpretation: Both household and hospital-based food insecurity were highly prevalent among caregivers. To reduce caregiver distress, hospitals need to consider reducing barriers for caregivers in obtaining food for themselves during their child's admission.

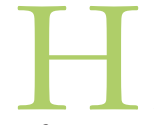
ousehold food insecurity, defined as unreliable access to sufficient quantities of affordable and nutritious food, affects 1 in 6 children under the age of 18 in Canada. ${ }^{1}$ It has been associated with multiple negative health outcomes in children, including behavioural problems, developmental delay and decreased academic performance and school engagement. ${ }^{2-8}$ Children who experience food insecurity are likely to be sick more frequently and be hospitalized more often. ${ }^{9}$ There are concerns of increased rates of food insecurity during the COVID-19 pandemic, ${ }^{10,11}$ but no evidence to date appears to have specifically addressed families with children with acute or chronic illness at this time.

Hospital-based food insecurity is defined as the inability of caregivers to obtain adequate healthy food, or enough to eat, during their child's hospital stay. ${ }^{12,13}$ Food insecurity is also associated with poorer health among adults, including caregiver distress. ${ }^{1}$ Hospital-based food insecurity may interfere with the caregivers' ability to play an active role in family-centred care as they may be hungry. Caregiver hospital-based food insecurity has not been well studied. In a recent study in the United States before the COVID-19 pandemic, about one-third of caregivers reported hospital-based food insecurity. ${ }^{12,13}$ Little is known about hospital-based food insecurity in the Canadian setting, or in the context of the COVID-19 pandemic. Understanding hospital-based food insecurity is important to inform health system policies to support caregivers optimally during pediatric hospital admissions.

Given the high prevalence of household food insecurity in Canada, potentially exacerbated during the COVID-19 pandemic, we hypothesized a high prevalence of hospital-based food insecurity in Canadian hospitals. This hypothesis is further supported by the fact that parents need to buy their own food when their child is admitted to hospital, and parents of children with a chronic illness already have high financial burdens. ${ }^{14}$ Our study objective was to determine the prevalence

\section{Competing interests: None declared.}

This article has been peer reviewed.

Correspondence to: Meta van den Heuvel, mathilda.vandenheuvel@ sickkids.ca

CMAJ Open 2022 February 8. DOI:10.9778/cmajo.20210223 
of household and hospital-based food insecurity in our hospital setting. Furthermore, we investigated the association between food insecurity and caregiver distress during a child's hospital admission and overall caregiver experiences about their food situation during their child's hospital stay.

\section{Methods}

\section{Study design}

We used a cross-sectional, survey-based study design and followed the Checklist for Reporting Results of Internet E-Surveys (CHERRIES) ${ }^{15}$ and Standards for Reporting Qualitative Research (SRQR). ${ }^{16}$

\section{Setting and participants}

The study setting was the general pediatric inpatient unit of the Hospital for Sick Children in Toronto, Ontario, from April through October 2020. The Hospital for Sick Children is the largest academic pediatric hospital in Canada and serves children aged 0 to 18 years. The research assistant (N.Z.) approached all caregivers with a child admitted to the general pediatric ward by calling the guardian identified in the child's electronic medical record. Participating caregivers had to be able to understand English and have Internet access to participate. There was no minimum length of hospital stay to participate in our study.

\section{Procedure}

Caregivers were given a recruitment letter upon hospital admission that informed them that the study explored food insecurity (Appendix 1, available at www.cmajopen.ca/content /10/1/E82/supp1/DC1). The research assistant (N.Z.) contacted the caregiver identified in the electronic medical record by phone 24-48 hours after admission and asked for consent to participate. No telephone messages were left about the study. One caregiver per household consented via a REDCap survey link. We invited this caregiver to complete the survey during admission or after discharge. We sent 3 reminders to complete the survey. No incentives were offered.

\section{Data sources}

Two authors (M.v.d.H., C.S.B.) designed the survey (Appendix 2 and Appendix 3, available at www.cmajopen.ca/content/10/1/ E82/suppl/DC1), which included validated measures of food insecurity and caregiver stress. One author (N.Z.) reviewed the electronic health records for children whose caregiver participated in the study. If there was any unclarity, another author (M.v.d.H) also reviewed the electronic health record.

\section{Measures}

\section{Exposure}

We measured household food insecurity with the 18-item US Household Food Security Survey Module (HFSSM). ${ }^{17}$ The HFSSM is included in the Canadian Community Health Survey. This module includes 10 adult-specific and 8 child-specific questions. We classified caregivers as food secure (no items affirmed) or marginally ( 1 positive response), moderately ( $2-5$ positive responsive) or severely food insecure ( $>6$ positive responses). ${ }^{1}$

No validated screening tool appeared to be available to measure hospital-based food insecurity. Therefore, we adapted 3 questions from the HFSSM to identify hospital-based food insecurity. For example; if the HFSSM question was "I/we could not afford balanced meals in the last 12 months," we adapted the question to "I/we could not afford balanced meals during my child's hospital admission." We chose these specific 3 questions to elucidate the severity of the hospital-based food insecurity (Table 1). Scoring was similar to the scoring of HFSSM.

\section{Outcome}

We measured caregiver distress with the overall distress score and the "Practical Problems" subscale of the Distress Thermometer for Parents (DT-P) developed by Haverman and colleagues ${ }^{18,19}$ in 2013 . The DT-P is a well-validated questionnaire used in diverse populations of parents with chronically ill children. ${ }^{18}$ The DT-P is strongly related to the Hospital Anxiety and Depression scale $(0.55 \leq r \leq 0.61)$ and moderately-to-strongly related to the Parenting Stress Index $(0.38 \leq r \leq 0.43) .{ }^{18}$ Numerous studies have used the DT-P to measure caregiver distress in parents of children with different pediatric chronic health conditions..$^{20,21}$

For the overall distress score, caregivers indicated how much distress they perceived in the previous week on a thermometer, where 0 indicated "no distress" and 10 indicated "extreme distress." Studies have identified a cut-off score of 4 to 5 to detect substantial caregiver distress. ${ }^{18,19}$ In our analysis, we measured caregiver distress as a continuous variable.

\section{Covariates}

We asked caregivers 25 general sociodemographic questions that were based on the Canadian Community Health Survey. ${ }^{22}$ Caregivers reported on the number of children in their household, their ethnicity, employment status, household income and their own health status. We collected details about the child's chronic condition, duration and month of admission from the electronic health record.

We identified potential confounders in the relation between food insecurity and caregiver stress a priori. ${ }^{21} \mathrm{We}$ included the following covariates in our analysis: child age, child's chronic condition (yes or no), duration of admission, caregiver's own health status, employment status, household income, single-parent household and number of children. ${ }^{23}$ The month of admission was relevant given the 1-caregiver

Table 1: Hospital-based food insecurity questions

1. I/we could not afford to eat balanced meals during my child's hospital admission

2. Did you or other adults in your household ever cut the size of your meals or skip meals during the hospital admission, because there wasn't enough money for food?

3. During the hospital admission, were you ever hungry, but didn't eat because there wasn't enough money for food? 
policy implemented during the COVID-19 pandemic, affecting our study from April to June 2020. This difference could have affected caregiver access to food.

\section{Qualitative component}

To explore caregivers' experiences obtaining food in more detail, we included 1 open-ended question in our survey: "Do you have any other feedback regarding your food situation during your child's hospital admission?”

\section{Data analysis}

We used descriptive statistics to assess the sociodemographic characteristics and the proportions of caregivers with household or hospital-based food insecurity. We compared categorical variables between caregivers who reported household food security and food insecurity. We used linear regression models to explore the association between household (adult and child) food insecurity, hospital-based food insecurity and caregiver distress during admission. In the regression models, we used both household and hospital-based food insecurity as continuous variables. We conducted an unadjusted analysis and a model adjusted for all covariates. We used variance inflation factors to assess multicollinearity. We performed multiple imputation with 15 imputed data sets using the multivariate imputation by chained equations (mice) package in $\mathrm{R}$ to overcome bias that may result from missing data, and combined the estimates across the 15 data sets using Rubin's rules. We tested for interactions between food insecurity and caregiver distress and the child's duration of admission or chronic condition. All $p$ values were 2-tailed and statistical significance was set at 0.05 . We used $\mathrm{R}$ version 4.0.2 for all analyses.

We used a thematic approach to explore the answers to the 1 open-ended question about caregivers' experiences obtaining food during hospital admission. Two authors (M.v.d.H., N.Z.) independently reviewed answers. These 2 authors identified and independently categorized common themes related to hospital-based food insecurity using NVivo software (version 12), which were then reviewed with all other authors.

\section{Ethics approval}

This study was approved by the research ethics board from the Hospital for Sick Children, Toronto.

\section{Results}

From April to October 2020, 1340 children were admitted to our general pediatric ward. We successfully contacted 851 caregivers by telephone. Of these, 775 (91.1\%) caregivers gave consent to participate, and $430(50.5 \%)$ completed at least part of the survey. Of the participants who completed part of the survey, $44(10.2 \%)$ did not fully complete the HFSSM (Figure 1).

\section{Food insecurity}

Of the 386 caregivers who completed the HFSSM, household food insecurity was reported by $132(34.2 \%)$ caregivers and for 76 (19.7\%) children; 147 (38.1\%) caregivers reported hospitalbased food insecurity. Table 2 describes the severity of

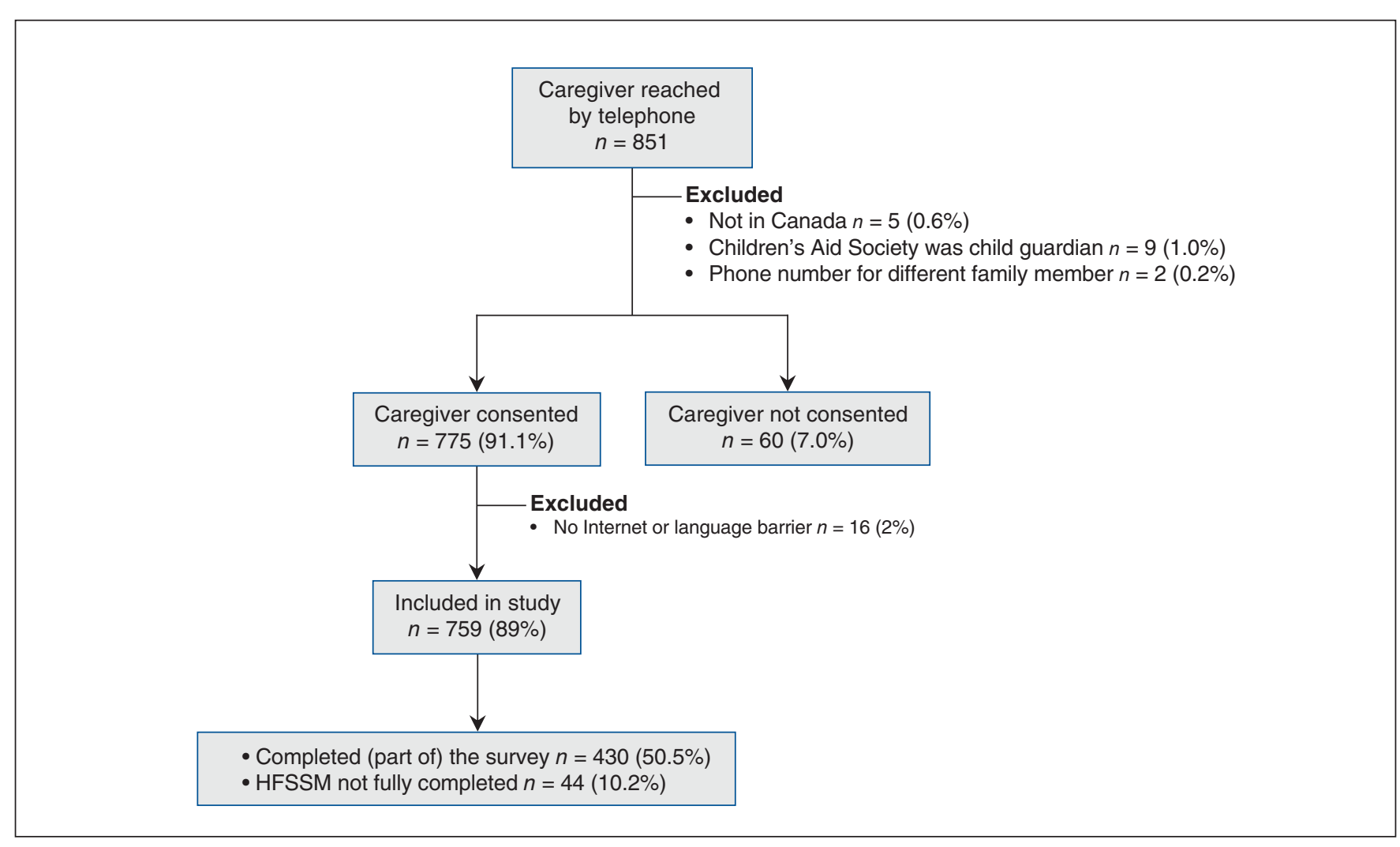

Figure 1: Study flow diagram. Note: HFSSM = Household Food Security Survey Module. 
household and hospital-based food insecurity. Both household and hospital-based food insecurity was reported by 96 $(24.9 \%)$ caregivers. Table 3 describes the sociodemographic characteristics of caregivers reporting food insecurity and those reporting food security.

\section{Caregiver distress}

Both household and hospital-based food insecurity were significantly associated with caregiver distress, independent of covariates. In the adjusted model, each affirmative answer on the 10 adult questions of the HFSSM was associated with a 0.21 (95\% confidence interval [CI] 0.07 to 0.36 ) increase in caregiver distress score. Each affirmative answer on the 8 child questions of the HFSMM was associated with a 0.38 (95\% CI 0.10 to 0.66 ) increase in caregiver distress score. Each affirmative answer on the 3 hospital-based food insecurity questions was associated with a $0.56(95 \% \mathrm{CI} 0.30$ to 0.83$)$ increase in caregiver distress score (Table 4; see Appendix 4, Appendix Tables 1-3, available at www.cmajopen.ca/content/10/1/E82/ suppl/DC1, for full covariate effects).

A stratified analysis, adjusted for all covariates, showed that the association between adult food insecurity and caregiver distress was stronger for households of children without a chronic condition ( $\beta=0.42,95 \%$ CI 0.09 to 0.76 ) than those of children with a chronic condition $(\beta=0.11,95 \% \mathrm{CI}-0.06$ to 0.27 ). Other interactions were nonsignificant (data available upon request).

\section{Caregivers' experiences obtaining food during hospital admission}

In total, 71 (18.4\%) of 386 parents answered the open-ended question regarding their food situation in the hospital. We identified multiple themes, presented in Table 5 .

\section{Financial burden obtaining food}

Many caregivers commented on the high expense of food in the hospital. They often felt the need to sacrifice their own food intake and skip meals, or to purchase inexpensive and unhealthy foods. Caregivers also described having to prioritize other expenses related to hospital admission, such as parking costs, over food.

\section{Emotional and practical barriers obtaining food}

Caregivers reported that they did not want to leave their child's room and did not want to take up the nurse's time to supervise their child. A subtheme also emerged around caregiver restrictions in the hospital related to COVID-19. Caregivers lacked assistance on how to access food for themselves during their child's admission.

\section{Caregiver stress obtaining food}

Caregivers described their increased stress in finding affordable food for themselves, in addition to the stress of their child's hospital admission.

\section{Advocacy for food for parents}

Many caregivers advocated for food to be provided to parents during their child's hospital admission. They articulated that this would recognize that caregivers are an important part of the child's care.

\section{Interpretation}

Our study explored the prevalence of household and hospitalbased food insecurity in a large sample of caregivers, and its relationship with distress in caregivers during their child's hospital admission. The results showed both a high prevalence of household (34\%) and hospital-based (38\%) food insecurity among caregivers; a quarter of the caregivers experienced both types of food insecurity.

The prevalence of food insecurity identified in our study is similar to that reported in a 2018-2019 study from a children's hospital in Texas, where $38 \%$ of caregivers reported household food insecurity and $43 \%$ reported hospital-based food

\begin{tabular}{|c|c|c|c|}
\hline \multirow[b]{2}{*}{ Variable* } & \multicolumn{2}{|c|}{ Household food insecurity $†$} & \multirow{2}{*}{$\begin{array}{c}\text { Hospital-based food insecurity } \\
\text { No. }(\%) \text { of caregivers } \\
n=386\end{array}$} \\
\hline & $\begin{array}{c}\text { No. }(\%) \text { of adults } \\
n=386\end{array}$ & $\begin{array}{c}\text { No. }(\%) \text { of children } \\
n=386\end{array}$ & \\
\hline Food secure & $254(65.8)$ & $310(80.3)$ & $239(61.9)$ \\
\hline Food insecure & $132(34.2)$ & $76(19.7)$ & $147(38.1)$ \\
\hline Marginal food insecurity & $51(13.2)$ & $38(9.8)$ & $67(17.4)$ \\
\hline Moderate food insecurity & $57(14.8)$ & $34(8.8)$ & $36(9.3)$ \\
\hline Severe food insecurity & $24(6.2)$ & $4(1.0)$ & $44(11.4)$ \\
\hline \multicolumn{4}{|c|}{$\begin{array}{l}\text { *Based on Food Insecurity Policy Research (PROOF) scoring method, }{ }^{1} \text { for adult items, } 1 \text { positive response considered marginal food } \\
\text { insecurity, } 2-5 \text { positive responses considered moderate food insecurity and } 6 \text { or more positive responses considered severe food insecurity. } \\
\text { For child items, } 1 \text { positive response considered marginal food insecurity, } 2-4 \text { positive responses considered moderate food insecurity and } 5 \text { or } \\
\text { more positive responses considered severe food insecurity. For hospital-based food insecurity items, } 1 \text { positive response considered marginal } \\
\text { food insecurity, } 2 \text { positive responses considered moderate food insecurity and } 3 \text { positive responses considered severe food insecurity. } \\
\text { tCaregivers reported on household food security of adults ( } 10 \text { items) and children ( } 8 \text { items) in the household, and on hospital-based food } \\
\text { security of caregivers ( } 3 \text { items). }\end{array}$} \\
\hline
\end{tabular}


Research

\section{Table 3: Sociodemographic characteristics by food security status}

\begin{tabular}{|c|c|c|c|c|}
\hline \multirow[b]{2}{*}{ Characteristic } & \multirow[b]{2}{*}{$\begin{array}{c}\text { No. (\%) missing } \\
n=430\end{array}$} & \multicolumn{3}{|c|}{ No. $(\%)$ of caregivers* } \\
\hline & & $\begin{array}{l}\text { Total study population } \\
\qquad n=430\end{array}$ & $\begin{array}{c}\text { Food insecure } \dagger \\
\quad n=143\end{array}$ & $\begin{array}{c}\text { Food secure } \dagger \\
n=243\end{array}$ \\
\hline Child age, mo, mean \pm SD & $2(0.5)$ & $78.2(71.3)$ & $83.7(73.8)$ & $75.0(70.0)$ \\
\hline Child with a chronic health condition & $1(0.2)$ & $257(59.9)$ & $91(63.6)$ & $138(57.0)$ \\
\hline Single-parent household & $0(0)$ & $62(14.4)$ & $36(25.2)$ & $18(7.4)$ \\
\hline Maternal ethnicity & $0(0)$ & & & \\
\hline European & & $147(34.2)$ & $33(23.1)$ & $1042.8)$ \\
\hline East Asian & & $43(10.0)$ & $6(4.2)$ & $34(14.0)$ \\
\hline South and Southeast Asian & & $94(21.9)$ & $36(25.2)$ & $46(18.9)$ \\
\hline Black & & $32(7.4)$ & $18(12.6)$ & $8(3.3)$ \\
\hline Arabic & & $32(7.4)$ & $12(8.4)$ & $15(6.2)$ \\
\hline Latin American & & $21(4.9)$ & $11(7.7)$ & $10(4.1)$ \\
\hline Indigenous & & $10(2.3)$ & $4(2.8)$ & $6(2.5)$ \\
\hline Other & & $51(11.9)$ & $23(16.1)$ & $20(8.2)$ \\
\hline Employment & $0(0.0)$ & & & \\
\hline Both caregivers employed full time & & $89(20.7)$ & $8(5.6)$ & $76(31.3)$ \\
\hline One caregiver employed full time & & $212(49.3)$ & $70(49.0)$ & $124(51.0)$ \\
\hline Both caregivers employed part time & & $8(1.9)$ & $4(2.8)$ & $3(1.2)$ \\
\hline Neither caregiver employed & & $31(7.2)$ & $23(16.1)$ & $6(2.5)$ \\
\hline Other (e.g., parental leave) & & $90(20.9)$ & $38(26.6)$ & $34(14.0)$ \\
\hline Number of children & $9(2.1)$ & $2.2(1.2)$ & $2.5(1.4)$ & $2.0(1.0)$ \\
\hline Family income before tax, $\$$ & $71(16.5)$ & & & \\
\hline 0 to 39999 & & $104(29.0)$ & $64(49.2)$ & $30(15.2)$ \\
\hline 40000 to 79999 & & $86(24.0)$ & $39(30.0)$ & 38 (19.3) \\
\hline 80000 to 149999 & & $101(28.1)$ & $22(16.9)$ & $67(34.0)$ \\
\hline$\geq 150000$ & & $69(18.9)$ & $5(3.8)$ & $62(31.5)$ \\
\hline Trouble making ends meet & $10(2.3)$ & $157(37.4)$ & $96(68.6)$ & $42(17.5)$ \\
\hline Trouble paying electricity, heat or telephone bill & $7(1.6)$ & & & \\
\hline Never true & & $270(63.8)$ & $47(33.1)$ & $201(83.4)$ \\
\hline Sometimes true & & $127(30.0)$ & $77(54.2)$ & $36(14.9)$ \\
\hline Often true & & $26(6.1)$ & $18(12.7)$ & $4(1.7)$ \\
\hline Housing & $4(0.9)$ & & & \\
\hline Owned & & $251(58.9)$ & $53(37.6)$ & $183(75.3)$ \\
\hline Paying rent & & $170(39.9)$ & $87(61.7)$ & $57(23.5)$ \\
\hline Other & & $5(1.2)$ & $1(0.7)$ & $3(1.2)$ \\
\hline Caregiver's own health & $4(0.9)$ & & & \\
\hline Fair or poor & & $64(15.0)$ & $39(27.3)$ & $17(7.1)$ \\
\hline Excellent, very good or good & & $362(85.0)$ & $104(72.7)$ & 224 (92.9) \\
\hline Month of admission & $1(0.2)$ & & & \\
\hline April & & $50(11.7)$ & 19 (13.3) & $30(12.4)$ \\
\hline May & & $90(21.0)$ & $35(24.5)$ & $46(19.0)$ \\
\hline June & & $75(17.5)$ & $30(21.0)$ & $38(15.7)$ \\
\hline July & & $61(14.2)$ & $15(10.5)$ & $40(16.5)$ \\
\hline August & & $63(14.7)$ & $18(12.6)$ & $36(14.9)$ \\
\hline September & & $60(14.0)$ & $14(9.8)$ & $36(14.9)$ \\
\hline October & & $30(7.0)$ & $12(8.4)$ & $16(6.6)$ \\
\hline Duration of admission, $d$, mean \pm SD & $5(1.2)$ & $5.4(5.7)$ & $5.5(5.6)$ & $5.4(6.0)$ \\
\hline Minimum, maximum & & 0,40 & 0,39 & 0,40 \\
\hline 25th percentile & & 2 & 2 & 2 \\
\hline 75th percentile & & 6 & 7 & 6 \\
\hline $\begin{array}{l}\text { Note: HFSSM }=\text { Household Food Security Survey Modu } \\
\text { *Unless indicated otherwise. } \\
\text { †Caregivers were identified as household food secure if } \\
\text { caregivers did not complete the HFSSM and food secur } \\
\text { †Study finished on Oct. } 20,2020 \text {. }\end{array}$ & $\begin{array}{l}\text { standard deviation. } \\
\text { not have any affirma } \\
\text { was not calculated. }\end{array}$ & ns on both the adult and $c$ & estions of the HFS & -four (10.2\%) \\
\hline
\end{tabular}


Table 4: Association between household and hospital-based food insecurity and caregiver distress using linear regression*

\begin{tabular}{|c|c|c|}
\hline \multirow[b]{2}{*}{ Food insecurity } & \multicolumn{2}{|c|}{ Difference in caregiver distress score $(95 \% \mathrm{Cl})$} \\
\hline & Unadjusted & Adjusted $†$ \\
\hline Adult household score $(0-10)$ & $0.19(0.07$ to 0.32$)$ & $0.21(0.07$ to 0.36$)$ \\
\hline Child household score (0-8) & $0.33(0.09$ to 0.58$)$ & $0.38(0.10$ to 0.66$)$ \\
\hline Hospital-based score (0-3) & $0.57(0.33$ to 0.81$)$ & $0.56(0.30$ to 0.83$)$ \\
\hline \multicolumn{3}{|c|}{$\begin{array}{l}\text { Note: } \mathrm{Cl}=\text { confidence interval, HFSSM = Household Food Security Survey Module. } \\
\text { "Models included } 386 \text { caregivers who completed HFSSM and measured change in caregiver distress score (0 to 10) for each affirmative answer on the food } \\
\text { insecurity measure. } \\
\dagger \text { Adjusted for caregiver's own health, employment status, household income, single-parent household, number of children, month of admission, child age, child's } \\
\text { chronic condition and duration of admission. }\end{array}$} \\
\hline
\end{tabular}

insecurity. ${ }^{13}$ Compared with the general Canadian population, food insecurity was much more common among participants in our study. In the latest annual report from Food Insecurity Policy Research (PROOF) Canada (2017-2018), household food insecurity among households with children was $16.2 \% .{ }^{1}$ The higher prevalence found in our study may be related to the timing of survey administration during the COVID-19 pandemic. However, our prevalence is still much higher than recent estimates of food insecurity during COVID-19; Statistics Canada found that $19.2 \%$ of families living in households with children reported food insecurity during the same period. ${ }^{11}$

Caregivers in our study may have had increased financial costs, as has been previously reported for caregivers with a chronically ill child. ${ }^{14,24}$ In contrast to medical costs, rent and utilities, food costs are variable and families may cut down on their food as a way to afford paying additional costs. Hospital admission itself adds to the burden of expenses, as parents in our study endorsed additional hospital-related financial stressors, such as transport and parking.

Our study showed that caregiver distress increased as food insecurity increased. Interestingly, the association between adult food insecurity and caregiver distress was not significant in children with a chronic condition. This may be because these caregivers have access to social work and other funding opportunities. Alternatively, caregivers of children with chronic conditions may already have higher levels of caregiver stress or be used to being food insecure. High caregiver distress is associated with a child's maladjustment to illness and adherence with medical treatment. ${ }^{18}$ High caregiver distress may also affect participation in family-centred care. A previous study by Jones and colleagues ${ }^{23}$ reported that greater perceived fulfillment of caregiver needs during hospital admission is associated with greater participation in hospital care. Consequently, patients of families with hospital-based food insecurity may experience a lower quality of family-centred care and be at risk for poorer child health outcomes.

Many caregivers provided written feedback about their food situation in the hospital. Although we could not identify any previous Canadian literature with which to compare our identified themes, a previous study from Manchester, England, identified similar themes regarding the expense of buying food and parents' ambiguity; this study also noted that despite the contribution parents make to the work of caring for their children, they were not entitled to discounted meals. ${ }^{25} \mathrm{~A}$ more recent study in the US reported that parents agreed that the child's needs come first, but parents need to eat to help their children. ${ }^{13}$ This parallels what caregivers in our study acknowledged, namely that parents need to eat to be able to take part in the care of their child during hospital admission.

Most caregivers with food insecurity reported both household and hospital-based food insecurity. Clinicians need to be aware of this overlap. When identifying families with social needs, clinicians should also inquire about immediate, hospitalbased food insecurity and offer resources (e.g., meal vouchers), when available, to families to alleviate this concern.

\section{Limitations}

Limitations of our study include nonresponse bias. We informed caregivers about the study topic before they gave consent, and families without food insecurity may have been less inclined to participate. However, our results may have also underestimated the incidence of food insecurity, as we excluded non-English speaking families and families who did not have Internet access. Also, we did not collect any information on referrals to social workers who may have been able to provide meal vouchers. In addition, the surveys were filled in per household, and we did not collect any details about the individual caregiver who answered the survey. Our results are reflective of food insecurity during the COVID-19 pandemic, about which there are no previous local data with which to compare rates of food insecurity. Given the cross-sectional nature of our study, we could not determine any causal relation.

\section{Conclusion}

Both household and hospital-based food insecurity were highly prevalent among caregivers with a child admitted to our academic pediatric hospital who participated in our survey. Future research should further explore the relation among food insecurity, family-centred care and child health outcomes. Hospitals need to consider reducing barriers for caregivers in obtaining food for themselves during their child's admission, such as offering nutritious food at a low cost and reducing other costs, such as parking, to reduce caregiver distress during their child's hospital stay. 
Table 5: Caregivers' experiences obtaining food during their child's hospital admission

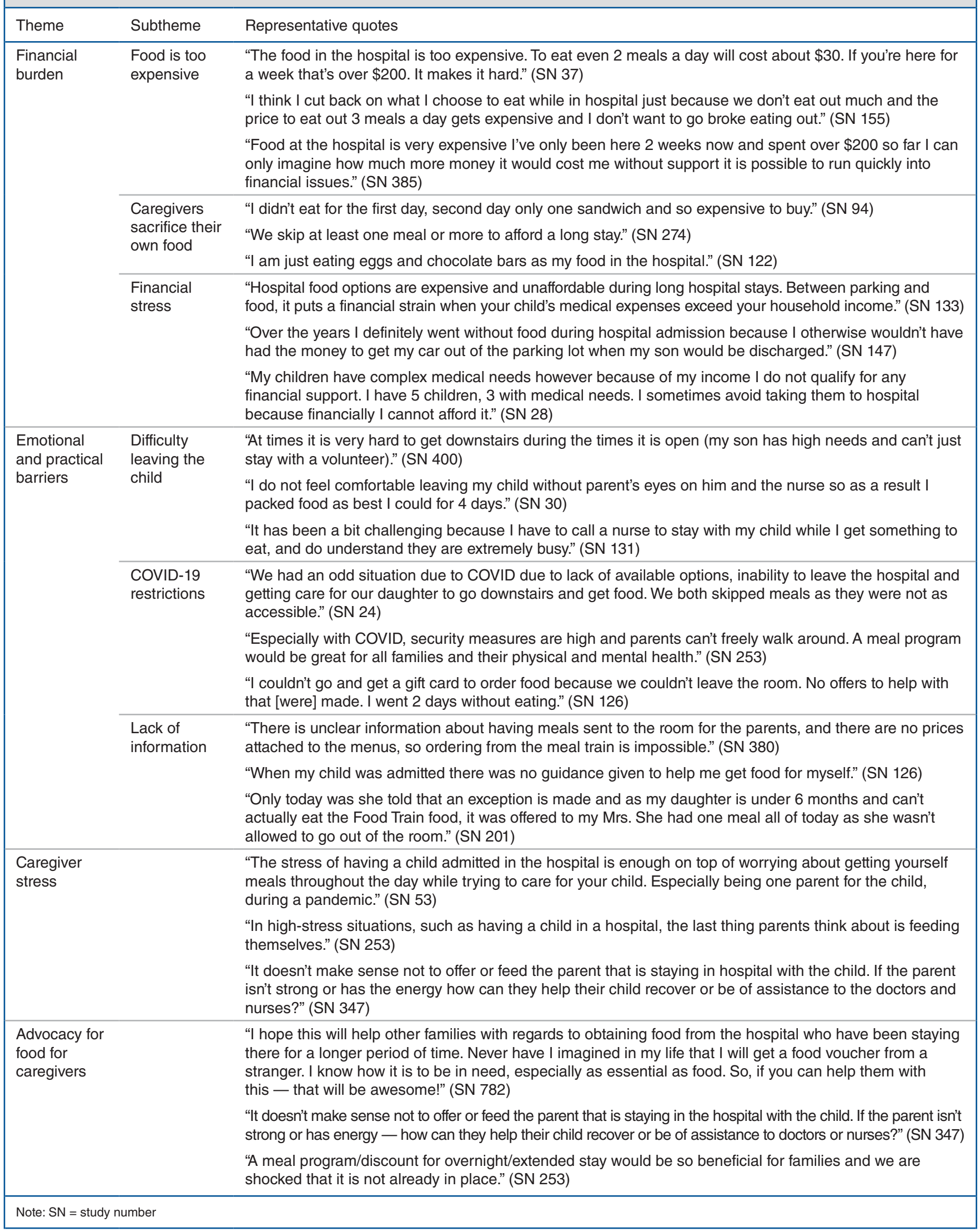




\section{References}

1. Tarasuk V, Mitchell A. Household food insecurity in Canada, 2017-2018. Toronto: PROOF, University of Toronto; 2020. Available: https://proof. utoronto.ca/resources/proof-annual-reports/household-food-insecurity-in -canada-2017-2018/ (accessed 2020 Nov. 19).

2. Alaimo K, Olson CM, Frongillo EA Jr. Food insufficiency and American school-aged children's cognitive, academic, and psychosocial development. Pediatrics 2001;108:44-53.

3. Shankar P, Chung R, Frank DA. Association of food Insecurity with children's behavioral, emotional, and academic outcomes: a systematic review. 7 Dev Behav Pediatr 2017;38:135-50.

4. Jyoti DF, Frongillo EA, Jones SJ. Food insecurity affects school children's academic performance, weight gain, and social skills. 7 Nutr 2005;135:2831-9.

5. Franklin B, Jones A, Love D, et al. Exploring mediators of food insecurity and obesity: a review of recent literature. 7 Community Health 2012;37:253-64.

6. Kaur J, Lamb MM, Ogden CL. The association between food insecurity and obesity in children: the National Health and Nutrition Examination Survey. 7 Acad Nutr Diet 2015;115:751-8.

7. Cook JT, Frank DA, Berkowitz C, et al. Food insecurity is associated with adverse health outcomes among human infants and toddlers. $7 \mathrm{Nutr}$ 2004;134:1432-8.

8. Melchior M, Chastang J-F, Falissard B, et al. Food insecurity and children's mental health: a prospective birth cohort study. PLoS One 2012;7:e52615.

9. Council on Community Pediatrics; Committee on Nutrition. Promoting food security for all children. Pediatrics 2015;136:e1431-8.

10. Who's bungry 2020: beyond COVID-19 - building a future without poverty. Toronto: Daily Bread Food Bank; 2020. Available: https://www.dailybread. ca/wp-content/uploads/2020/11/Whos-Hungry-Report-2020.pdf (accessed 2020 Nov.19).

11. Canadians experiencing food insecurity during the COVID-90 pandemic. Ottawa: Statistics Canada; 2020. Available: https://www150.statcan.gc.ca/n1/ pub/11-627-m/11-627-m2020042-eng.htm (accessed 2020 Nov. 19).

12. Makelarski JA, Thorngren D, Lindau ST. Feed first, ask questions later: alleviating and understanding caregiver food insecurity in an urban children's hospital. Am 7 Public Health 2015;105:e98-104.

13. Lee AM, Lopez MA, Haq H, et al. Inpatient food insecurity in caregivers of hospitalized pediatric patients: a mixed methods study. Acad Pediatr 2021; 21:1404-13.

14. Fuller AE, Brown NM, Grado L, et al. Material hardships and health care utilization among low-income children with special health care needs. Acad Pediatr 2019;19:733-9.

15. Eysenbach G. Improving the quality of Web surveys; the Checklist for Reporting Results of Internet E-Surveys (CHERRIES). 7 Med Internet Res 2004;6:e34.

16. O'Brien BC, Harris IB, Beckman TJ, et al. Standards for reporting qualitative research: a synthesis of recommendations. Acad Med 2014;89:1245-51.

17. Bickel G, Nord M, Price C, et al. Measuring food security in the United States: guide to measure household food insecurity. Alexandria (VA): United States Department of Agriculture, Food and Nutrition Service, Office of Analysis, Nutrition, and Evaluation; 2000. Available: https://naldc.nal.usda.gov/ download/38369/PDF (accessed 2020 Nov.19).

18. Haverman L, van Oers HA, Limpberg PF, et al. Development and validation of the distress thermometer for parents of a chronically ill child. $\mathcal{F}$ Pediatr 2013;163:1140-6.e2.

19. van Oers HA, Schepers SA, Grootenhuis MA, et al. Dutch normative data and psychometric properties for the distress thermometer for parents. Qual Life Res 2017;26:177-82.
20. Schepers SA, Sint Nicolaas SM, Maurice-Stam H, et al. Parental distress 6 months after a pediatric cancer diagnosis in relation to family psychosocial risk at diagnosis. Cancer 2018;124:381-90.

21. Diederen K, Haverman L, Grootenhuis MA, et al. Parental distress and quality of life in pediatric inflammatory bowel disease: implications for the outpatient clinic. $\mathcal{F}$ Pediatr Gastroenterol Nutr 2018;66:630-6.

22. Brcic V, Eberdt C, Kaczorowski J. Development of a tool to identify poverty in a family practice setting: a pilot study. Int 7 Family Med 2011;2011:812182.

23. Jones J, Nowacki AS, Greene A, et al. Investigating parent needs, participation, and psychological distress in the children's hospital. Hosp Pediatr 2017; 7:385-94.

24. Lindley LC, Mark BA. Children with special health care needs; Impact of health care expenditures on family financial burden. 7 Child Fam Stud 2010; 19:79-89.

25. Callery P. Paying to participate: Financial, social and personal costs to parents of involvement in their children's care in hospital. F Adv Nurs 1997; 25:746-52.

Affiliations: Department of Paediatrics (van den Heuvel, Fuller, Zaffar, Li, Beck, Birken), Faculty of Medicine, University of Toronto; Division of Paediatric Medicine (van den Heuvel, Fuller, Beck, Birken), and Child Health Evaluative Sciences (van den Heuvel, Zaffar, Li, Birken), The Hospital for Sick Children, Toronto, Ont.; Department of Health Research Methods, Evidence and Impact (Fuller), McMaster University, Hamilton, Ont.

Contributors: Meta van den Heuvel, Anna Fuller, Carolyn Beck and Catherine Birken designed the study. Meta van den Heuvel, Nusrat Zaffar and Catherine Birken contributed to data acquisition, and Meta van den Heuvel, Xuedi Li and Catherine Birken contributed to data analysis. Meta van den Heuvel, Anne Fuller, Carolyn Beck and Catherine Birken interpreted the data. Meta van den Heuvel drafted the manuscript. All of the authors revised the manuscript critically for important intellectual content, gave final approval of the version to be published and agreed to be accountable for all aspects of the work.

Funding: This research was supported by a Walmart Community Grant through the SickKids Foundation for a study on food insecurity in the inpatient hospital setting. These agencies had no role in the design, collection, analyses or interpretation of the results of this study or in the preparation, review, or approval of the manuscript.

Content licence: This is an Open Access article distributed in accordance with the terms of the Creative Commons Attribution (CC BY-NC-ND 4.0) licence, which permits use, distribution and reproduction in any medium, provided that the original publication is properly cited, the use is noncommercial (i.e., research or educational use), and no modifications or adaptations are made. See: https://creativecommons.org/licenses/ by-nc-nd/4.0/

Data sharing: All data presented in this manuscript are available to other investigators upon request to the corresponding author.

Acknowledgement: The authors thank all the families who participated in this research.

Supplemental information: For reviewer comments and the original submission of this manuscript, please see www.cmajopen.ca/content/ 10/1/E82/suppl/DC1. 